Phosphorus Research Bulletin Vol. 14 (2002), 15-22

\title{
ARCHITECTURE OF CRYSTALLINE ULTRAPHOSPHATES
}

\author{
DÖRTE STACHEL AND ANNETT OLBERTZ
}

Otto-Schott-Institut, Chemisch-Geowissenschaftliche Fakultät, FriedrichSchiller-Universität Jena, Fraunhoferstraße 6, D-07743 Jena, Germany

\begin{abstract}
Ultraphosphate structures are polymeric and consist of the anion framework and the cations between. But, the anion framework strongly depends on the cations, their charge, size, and value. Some selection rules exist, which point out the number of possible structure bonds related to the number and charge of the cations. Concerning anion framework, there exist discrete cyclic units as well as ribbons and layer structures with different ring sizes, number of connecting $\left\{\mathrm{PO}_{4}\right\}$ tetrahedra and connection possibilities. The cations are isolated from the others within the frameworks because of their low content. But, when the cations were connected each other with thinkable bonds, we get a detailed insight into the structure interactions between anion configurations and the cations between. In all evaluated crystalline ultraphosphate structures, the cations have 6 cations ,around" to form octahedra with different distances and symmetries from one cation to the next neighboured one. The so-called repeatable units seem to depend on the complexity of the anionic framework: the more complex the anionic structure, the less complicate the cationic relations, and reversed. This means, that ultraphosphate structures possess strong relations between the $\left\{\mathrm{PO}_{4}\right\}$ groups and the cations. The result are complex interconnecting structures.
\end{abstract}

\section{INTRODUCTION}

Ultraphosphates are situated in the region between the pure phosphorus pentoxide and the so-called metaphosphates. Where the structures of the phosphorus pentoxide constist of pure $\mathrm{Q}^{3}$ connected $\left\{\mathrm{PO}_{4}\right\}$ tetrahedra, the metaphosphate structures only contain $\mathrm{Q}^{2}$ connected $\left\{\mathrm{PO}_{4}\right\}$ groups. In the region between, $\mathrm{Q}^{3}$ as well as $\mathrm{Q}^{2}\left\{\mathrm{PO}_{4}\right\}$ tetrahedra occur. Ultraphosphates in early works [1] were indicated to be crystalline as well as glass-forming substances with a broad variety of relizable structures. But, within the last years was found, that some selection rules exist, which point out the number of possible structure bonds related to the number and charge of the cations [2]. The known general formula for ultraphosphates is given as:

$$
\mathrm{m} \mathrm{P} \mathrm{P}_{2}+\mathrm{n}\left[\mathrm{PO}_{3}\right]^{-} \text {or } \quad\left[\mathrm{P}_{(2 \mathrm{~m}+\mathrm{n})} \mathrm{O}_{(5 \mathrm{~m}+3 \mathrm{n})}\right]^{\mathrm{n}-}
$$

Received August 5, 2002; Accepted October 9, 2002 
and covers all compositions and structures without separate information about structures and connectivities.

The relation between $\mathrm{Q}^{3}$ and $\mathrm{Q}^{2}$ tetrahedra is strongly connected with the anion type and the charge of the cations in these structures, see table 1.

\section{TABLE 1:}

BASIC $Q^{3} / Q^{2}$ RATIOS IN DEPENDENCE ON THE ANION TYPE AND SUMMARIZED CHARGE OF CATIONS

\section{$\mathbf{Q}^{3} / \mathbf{Q}^{2}$ RATIO}

$2: 2$

$2: 3$

$2: 4$

$2: 5$

$2: 6$

\section{ANION TYPE}

$\left(\mathrm{P}_{4 \mathrm{x}} \mathrm{O}_{11 \mathrm{x}}\right)^{2 \mathrm{x}-}$

$\left(\mathrm{P}_{5 \mathrm{x}} \mathrm{O}_{14 \mathrm{x}}\right)^{3 \mathrm{x}-}$

$\left(\mathrm{P}_{6 \mathrm{x}} \mathrm{O}_{17 \mathrm{x}}\right)^{4 \mathrm{x}-}$

$\left(\mathrm{P}_{7 \mathrm{x}} \mathrm{O}_{20 \mathrm{x}}\right)^{5 \mathrm{x}-}$

$\left(\mathrm{P}_{8 \mathrm{x}} \mathrm{O}_{23 \mathrm{x}}\right)^{6 \mathrm{x}-}$

\section{CHARGE OF CATIONS (SUM)}

2

3

4

5

6

In table 2 are given the anion types together with the up to now known anion structures: layers, ribbons, and cyclic units. The numbers within the parentheses give the sizes of the rings, which are basic units of the complex anions.

\section{TABLE 2:}

ULTRAPHOSPHATE STRUCTURES DEPENDING ON ANION TYPES

$\begin{array}{llll}\text { ANION TYPE } & \text { LAYERS } & \text { RIBBONS } & \text { CYCLICS } \\ \left(\mathrm{P}_{4 \mathrm{x}} \mathrm{O}_{11 \mathrm{x}}\right)^{2 \mathrm{x}-} & {[10],[12+8],[14+6],[16+4]} & --- & -- \\ \left(\mathrm{P}_{5 \mathrm{x}} \mathrm{O}_{14 \mathrm{x}}\right)^{3 \mathrm{x}-} & {[12],[16+8],[20+8]} & {[[8]]} & -- \\ \left(\mathrm{P}_{6 \mathrm{x}} \mathrm{O}_{17 \mathrm{x}}\right)^{4 \mathrm{x}-} & {[14]} & --- & -- \\ \left(\mathrm{P}_{7 \mathrm{x}} \mathrm{O}_{20 \mathrm{x}}\right)^{5 \mathrm{x}-} & --- & {[[10]]} & \\ \left(\mathrm{P}_{8 \mathrm{x}} \mathrm{O}_{23 \mathrm{x}}\right)^{6 \mathrm{x}-} & --- & & {[[[6]]]}\end{array}$

Ultraphosphate structures are constructed after strong selection rules. The anions as well as the cations form with well defined principles several frameworks which represent stochiometries and the resulting structures. The stability of the spatial 
constructions seems to be a function of the properties of the cations, like charge, size, and polarizability. But, until now, no calculations were been done to this subject.

\section{CONSTRUCTION OF ULTRAPHOSPHATES WITH CYCLIC ANIONS}

The only known ultraphosphates with cyclic anions are of the type $\mathrm{Na}_{3} \mathrm{M}^{\mathrm{III}} \mathrm{P}_{8} \mathrm{O}_{23}$, where the $\mathrm{M}^{\mathrm{III}}$ can be: $\mathrm{Fe}, \mathrm{V}, \mathrm{Cr}, \mathrm{Mn}, \mathrm{Al}$, or $\mathrm{Ga}[3,4]$. Looking for the anions, they are arranged very similar to that of the cyclic metaphosphates, with the cations between, forming cation sub-units each. The $\mathrm{M}^{\mathrm{III}}$ „lattice“ includes 3 different distances, which results in alternating larger and smaller planes in the framework with äquidistant perpendicular planes. The $\mathrm{Na}^{+}$positions are very irregularily, represented by unique distances to each of the sodiums, but to the $\mathrm{M}^{\mathrm{III}}$ positions with 3 very different distances, where one of them is nearly the double of one other. This is the reason why this arrangement is not symmetric and very complex, see figures 1 and 2 .

FIGURE 1:

MOLECULAR ARRANGEMENT OF THE STRUCTURE GROUPS IN CYCLIC ULTRAPHOSPHATES

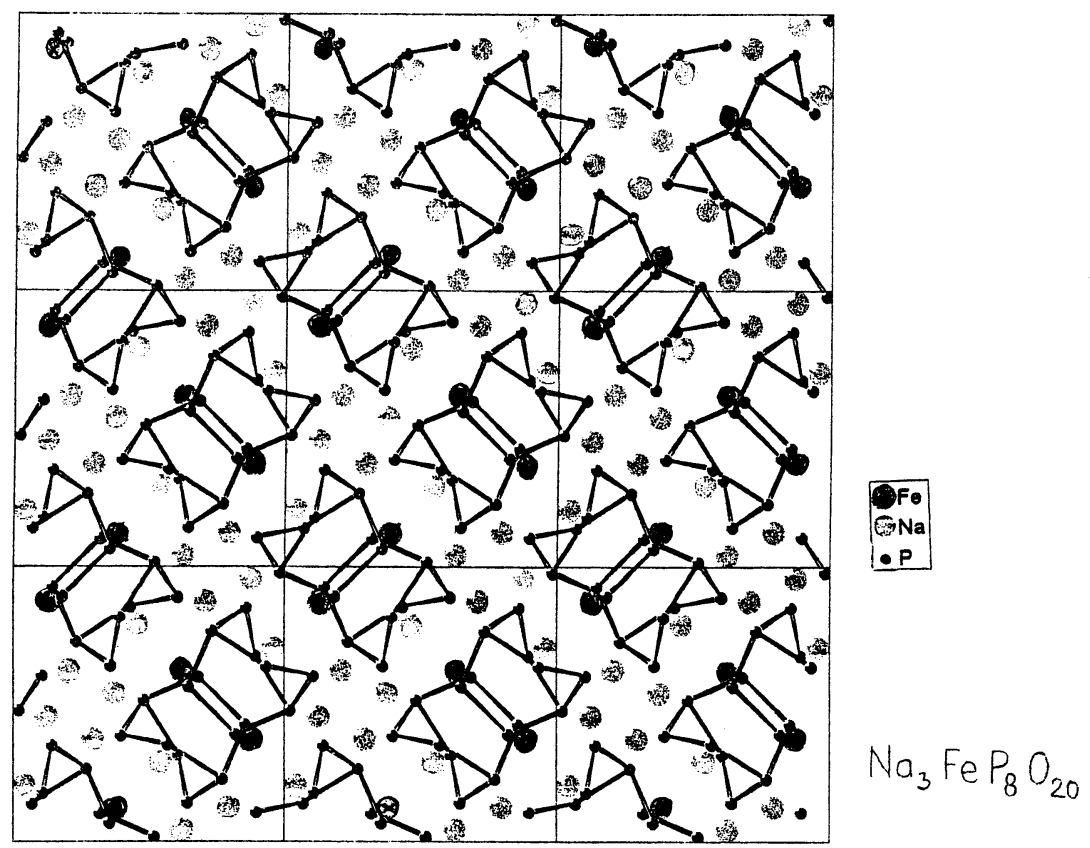


FIGURE 2:

ARRANGEMENT OF THE CATIONS IN CYCLIC ULTRAPHOSPHATES

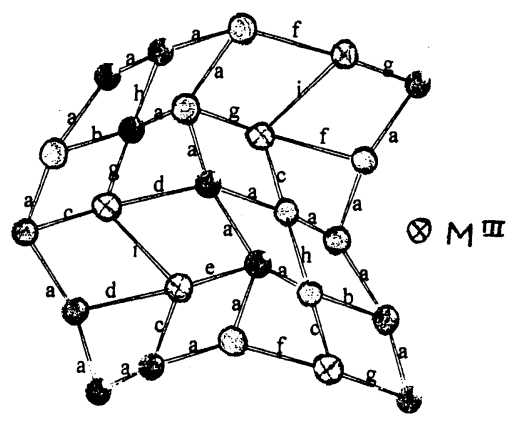

\section{CONSTRUCTION OF ULTRAPHOSPHATES WITH RIBBON ANIONS}

In the structure of $\mathrm{NiHP}_{5} \mathrm{O}_{14}$, the ribbons of the $\left\{\mathrm{PO}_{4}\right\}$ tetrahedra consist of 8 membered rings, which are oriented in parallel planes. The cations are situated between the ribbons and are normally shifted towards next plains. In the case of $\mathrm{NiHP}_{5} \mathrm{O}_{14}$, the hydrogens connect the ribbons via 10 membered rings between to built up planes [5], see figure 3.

FIGURE 3:

GENERAL VIEW AT THE STRUCTURE OF NiHP ${ }_{5} \mathrm{O}_{14}$

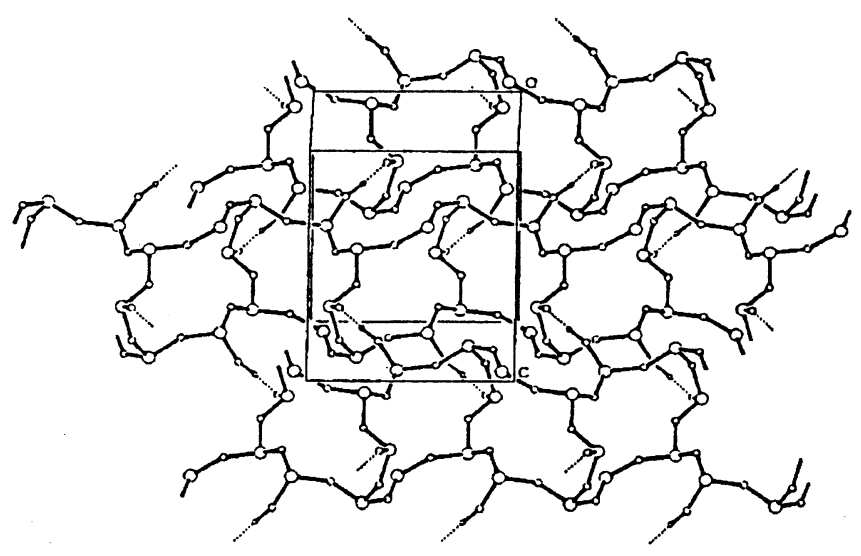

The height of these plains is given by $4\left\{\mathrm{PO}_{4}\right\}$ tetrahedra, forming waved layers. The cations are arranged between these planes parallel to $\mathrm{b}$ direction, see figure 4 . 
FIGURE 4

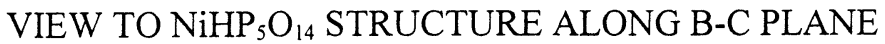

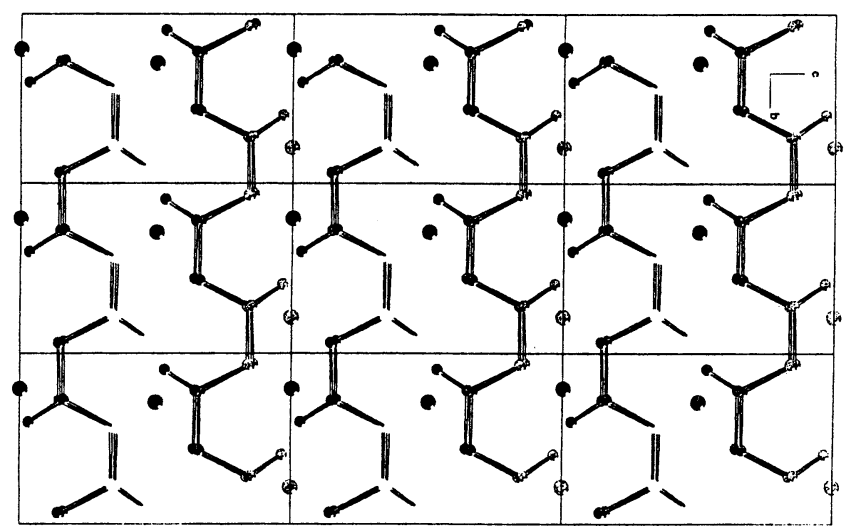

For the cations, there exist 3 possibilities for arrangements: $\mathrm{Ni}-\mathrm{Ni}, \mathrm{H}-\mathrm{H}$, and $\mathrm{Ni}-\mathrm{H}$. Each of these is relatively symmetric, in opposite to that structures with the discrete cyclic anions, see figure 5 .

\section{FIGURE 5}

CATIONIC ARRANGEMENT IN NiHP ${ }_{5} \mathrm{O}_{14}$ TYPICAL FOR Ni-H RELATION
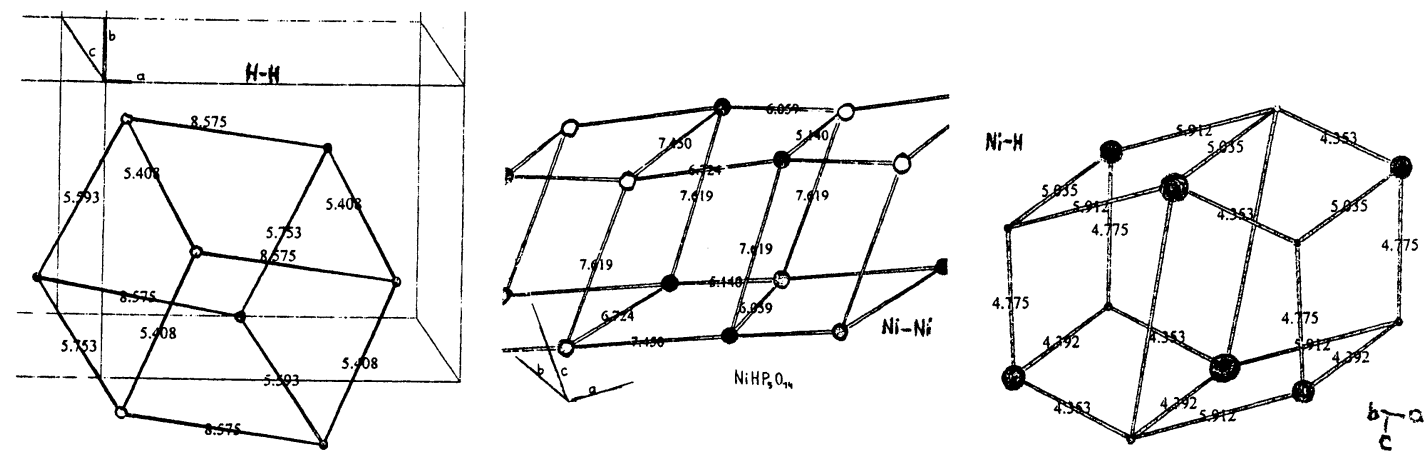

We can assume, that the cationic interactions in these ribbon-like structures depend on the anionic structure patterns as well on the containing cations $[6,7,8,9]$ itself. These interactions are complex, since more than one cation is included in the ribbon structures. In the $\mathrm{Fe}_{2} \mathrm{P}_{5} \mathrm{O}_{21}$ structure, there are 2 different oxidation states of iron. They occupy two different places within the structure: the bigger $\mathrm{Fe}^{2+}$ is arranged between the 10 membered rings of the ribbons, where the smaller $\mathrm{Fe}^{3+}$ is placed nearly inside these big rings. 


\section{CONSTRUCTION OF ULTRAPHOSPHATES WITH LAYER ANIONS}

The general construction of the anionic layers for the double-charged cations is given in figure 6. The difference between the anionic frameworks is defined by the different ring sizes, which built up these layers. We find the different combinations: $[10+10],[12+8],[14+6]$, and [16+4], given by the selection rules $[10,11]$. The cations are situated slightly above and below these waved planes, mostly in the neighbourhood of the bigger rings.

\section{FIGURE 6}

GENERAL ARCHITECTURE OF THE LAYER STRUCTURES $\left(\mathrm{M}^{\mathrm{II}} \mathrm{P}_{4} \mathrm{O}_{11}\right)_{x}$

$U P \mathrm{ZnP}_{4} \mathrm{O}_{11}[16+4]$

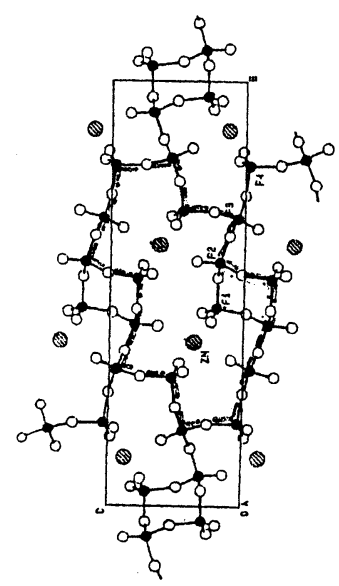

UP $\mathrm{MnP}_{4} \mathrm{O}_{11}[12+8]$

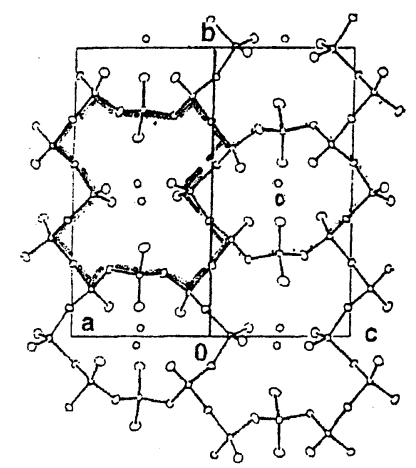

$\mathrm{UP} \mathrm{NiP} \mathrm{O}_{11}[14+6]$

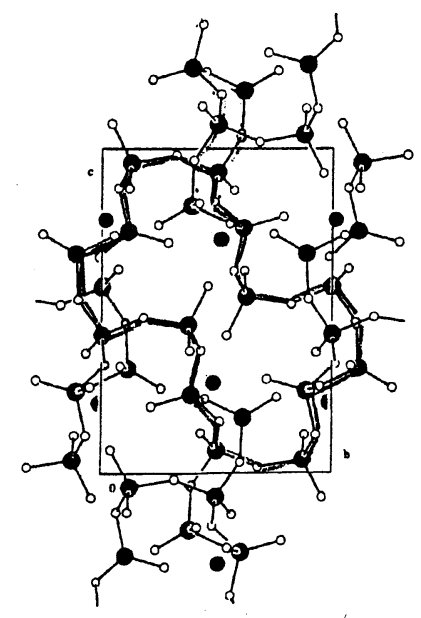

$\mathrm{UP} \mathrm{Cu}_{2} \mathrm{P}_{8} \mathrm{O}_{22}[10+10]$

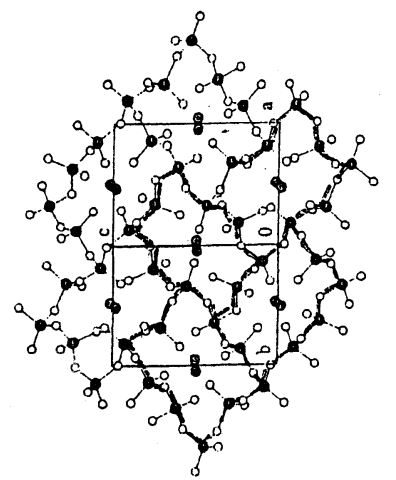

In the case of the copper ultraphosphate $\mathrm{Cu}_{2} \mathrm{P}_{8} \mathrm{O}_{22}$ [12], we find 2 positions of the $\mathrm{Cu}^{2+}$, having very simple arrangements together- nearly symmetric octahedral, see figure 7 . 
FIGURE 7

CATIONIC ARRANGEMENT IN THE $\mathrm{Cu}_{2} \mathrm{P}_{8} \mathrm{O}_{22}$ STRUCTURE

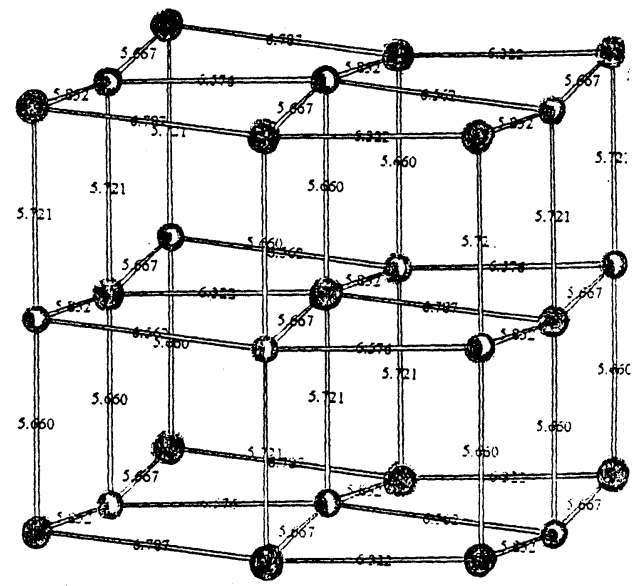

The arrangement of anionic layers together with the cations is shown in figure 8 .

There are two independend seeming structures, which are strongly interconnected.

\section{FIGURE 8}

GENERAL ARCHITECTURE OF THE $\mathrm{Cu}_{2} \mathrm{P}_{8} \mathrm{O}_{22}$ INTERCONNECTING STRUCTURE

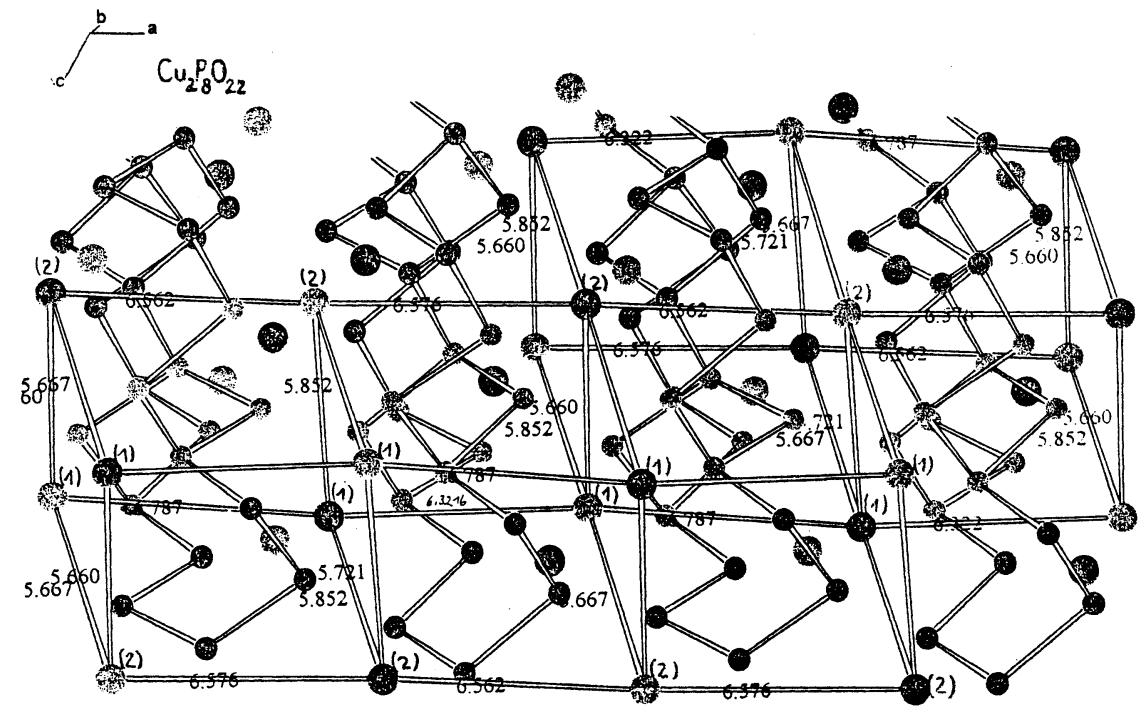




\section{CONCLUSIONS}

The spatial structure arrangements in crystalline ultraphosphates are very complex. The simpler the anionic structure, the more complicate is the cationic architecture and reversed. The anionic structure determines the cationic coordination. But, the anionic structure strongly depends on the cations and their properties. This maybe the reason why selection rules exist. Only cations with very similar properties can built analogous anionic arrangements, otherwise, the symmetry conditions will forbid their formation.

\section{REFERENCES}

1. J. R. Van Wazer, Interscience Publ., Inc., New York, London, 1958.

2. A. Olbertz, PhD Thesis, Jena 1998.

3. N. N. Chudinowa, K. K. Palkina, N. B. Komarovskaya, S. I.Maksimova, N. T. Chibiskova, Dokl. Akad. Nauk SSSR 306, 635-638 (1989).

4. N. N. Chudinowa, E. V. Muraschowva, N. B.Komarovskaya, Sintes i kristallitscheskaya struktura. Journal Neorg. Mater. 39 , 1769-1772 (1994).

5. A. Olbertz, D. Stachel, I. Svoboda, H. Fueß, Z.Kristallogr. 211,551-552 (1996).

6. A. Durif, Plenum Press (1995).

7. U. Hoppe, Thesis, Rostock 1997.

8. A. Olbertz, D. Stachel, Phosphorus Research Bulletin 10, 166-170 (1999).

9. A. Olbertz, D. Stachel, Phosphorus Research Bulletin 10, 161-165 (1999).

10. D. Stachel, A. Olbertz, Phosphorus Research Bulletin 10, 70-75 (1999).

11. A. Olbertz, D. Stachel, Phosphorus Research Bulletin 12, 191-202 (2001).

12. A. Olbertz, D. Stachel, I. Svoboda, H.Fueß, Acta Cryst. C 52,1603-1605 (1996).

13. G. Walter, U. Hoppe, T. Baade, R. Kranold, D. Stachel, J. Non-Cryst. Solids 217 , 299-307 (1997). 